IJMS 27(2), 27-46 (2020)

How to cite this article:

Awee, A., Mohsin, F. H., \& Makhbul, Z. M. (2020). The factors why people exert less: The relationship between workplace envy and social loafing moderated by self-esteem. International Journal of Management Studies, 27(2) July, 27-46. https://doi.org/10.32890/ijms.27.2.2020.7523

\title{
THE FACTORS WHY PEOPLE EXERT LESS: THE RELATIONSHIP BETWEEN WORKPLACE ENVY AND SOCIAL LOAFING MODERATED BY SELF-ESTEEM
}

\author{
AZEYAN AWEE* \\ FARHANA HANIM MOHSIN \\ Faculty of Business and Finance \\ Universiti Tunku Abdul Rahman (Perak Campus) \\ ZAFIR KHAN MOHAMED MAKHBUL \\ Faculty of Economics and Management \\ Universiti Kebangsaan Malaysia \\ *Corresponding author: azeyan@utar.edu.my
}

\begin{abstract}
The aim of this paper is to link envy at the workplace to social loafing and to examine the role of self-esteem in moderating this relationship. Data was collected via a survey questionnaire from 393 employees working in public and private organizations in Malaysia. Partial least squares-structural equation modeling (PLS-SEM) was used to test the hypotheses. The results show that the higher the degree of workplace envy encountered, the higher the inclination for members to exert less effort while working in a team (social loafing), and this relationship is moderated by self-esteem. In addition, it is found that the relationship is better for low self-esteem workers relative to those high in self-esteem. In terms of workplace envy and avoidance of social loafing, the research provides important implications. Organizations should etablish a supportive workplace that encourages employees to be
\end{abstract}


more involved and practice openness and give continued support. In a team culture especially, managers must play an active role by paying attention and being more sensitive towards circumstances that induce feelings of envy at work. By implementing a proper system and control, tendency towards workplace envy and social loafing can be mimimized.

Keywords: Workplace envy, social loafing, self-esteem, personality.

Received: 13/12/2019 Revised: 13/07/2020 Accepted: 29/07/2020 Published: 11/10/2020

\section{Introduction}

In today's organizations, success can be achieved not only through financial victory but also through physically and psychologically healthy human resources, especially with regards to emotions (González-Navarro, Zurriaga-Llorens, Tosin Olateju, \& LlinaresInsa, 2018). Hence, there has been a massive growth of interest in research and theory in the area of emotions in the context of the organization (Tyng, Amin, Saad, \& Malik, 2017). Prior studies have focused on a number of aspects of emotion, such as experiences and causes and consequences at work, and it is not uncommon because organizations consist of people and people do have emotions (Erdil, \& Müceldili, 2014). In the organizational behavior field, emotions are inseparable from employees' routine work and play a major role in how employees' behave and react at work. In order to succeed in the global environment, organizations must be concerned with employees' positive and negative emotions. However, a review of literature shows that many studies have been conducted on positive emotions, while negative emotions in the workplace have been neglected and have received little attention (Hökkä, Vähäsantanen \& Paloniemi, (2019). Acknowledging the negative emotions in the workplace is equally important because no organization is protected from the consequences of negative emotions. In fact, the risks of ignoring negative emotions are even greater as negative emotions are associated with organizational losses and events that impede the accomplishment of goals, which in turn, can increase the occurrence of workplace deviance (Pearson, 2017). Indeed, past investigations have demonstrated that these negative feelings are related to poor organizational performance, turnover issues, employee withdrawal and sabotage (Porath \& Pearson, 2012). One potentially important, 
yet virtually ignored emotion deserving attention in organizational behavior research, is the experience of envy (Duffy \& Shaw, 2000).

When someone desires or wants the attributes, accomplishments or assets of others, envy is enabled (Parrot \& Smith, 1993). Therefore, envy is prevalent in the workplace (Shu \& Lazatkhan, 2017; Smith \& Kim, 2007), particularly when employees perceive inequality in the distribution of the workload, job promotion and other resources for which they have to compete (Tai, Narayanan, \& McAllister, 2012). Envy may therefore have negative effects on workers taking action to counter the comparative advantages of those they envy (Duffy, Shaw, \& Schaubroeck, 2008). This is due to the fact that envy is an emotion that involves feelings of inferiority and misery. The aim of the envious person is to reduce his or her level of envy by reducing the gap between the envious and the envied (Heider, 1958). This is done by harming the other person that leads to counterproductive behavior. Undeniably, most research has shown that behavioral reactions to envy involve harming the other person (e.g., CohenCharash \& Mueller, 2007; Mouly \& Sankaran, 2002; Shu \& Lazatkhan, 2017), which inevitably and negatively influences work performance, absenteeism and turnover (Duffy \& Shaw, 2000). However, very few studies have acknowledged the inhibiting and destructive aspects of this emotion on social loafing which is there is tendency people exert less effort while working in group because of the impact of negative emotions in workplace such work place envy. Furthermore, negative emotions, suggest the effects of conflict on the overall group climate, but also reflect individual member's appraisal of the problematic interaction within the group. In fact, past studies on social loafing have mainly discussed how social loafing leads to negative effects on fellow group members (e.g., Aggarwal and O'Brien, 2008; Jassawalla, Sashital, and Malshe, 2009), and have attempted to understand why individuals would engage in this behavior and how it could be prevented. Although a number of researchers have discussed this issue or have presented theories on particular antecedents of social loafing (e.g., Uysal, 2019; Satvir, Huaqing, \& Min, 2017), the focus has been more on contextual factors, such as group cohesiveness, team size, task visibility, and others, rather than emotion factors, like workplace envy. According to Weiss \& Cropanzano (1996), based on the affective events theory (AET), employees often react emotionally to a work event, that in turn, has an effect on their work behavior. In addition, a person who experiences envy not only focuses on needing 
what other people have; they even consider removing or destroying the object of envy by using counterproductive behavior, such as social loafing.

Although workplace envy may lead to the occurrence of social loafing behavior, its effects may vary according to the personality traits (Shu \& Lazatkhan, 2017). In this study, we focus on self-esteem as a moderating variable, following Judge, Van Vianen, and De Pater's (2004) suggestion that self-esteem is one of the core self-evaluation factors related to an individual's emotional state. Generally, it is more likely that workers with favorable core self-evaluation would behave constructively (Tracy \& Robins, 2003). Individuals with high self-esteem treat envy as a reward for engaging in positive behavior and avoiding negative behavior, like social loafing, to progress to the point of their desired goal. In addition, when high self-esteem employees feel envious, they do not see envy as a risk, but focus on protecting their own self-image by reacting effectively (Duffy, Shaw, Scott, \& Tepper, 2006). In sum, this present study suggests that workplace envy predicts social loafing directly and indirectly through the personality trait of self -esteem. This research differs from prior studies in three ways. First, we focus on a negative emotion, i.e., workplace envy rather than a positive emotion to predict employees' behavior. Second, we examine the effect of workplace envy on social loafing, which is defined according to the affective event theory (AET) (Fishbein \& Ajzen, 1977). Third, we include self-esteem as a moderator to better explain the relationship between workplace envy and social loafing behavior.

\section{Literature Review}

\section{Workplace Envy and Social Loafing}

Workplace envy has become a part of the increasing workplace issues nowadays. Workplaceenvy does not only intimidate the organizational environment; it also affects the work performance in the organization, particularly those working in a team. Employees who are envious of other co-workers tend to engage in interpersonal counter-productive work behavior (Thompson, Glaso, \& Martinsen, 2016). It is assumed that a group setting would be a vulnerable setting for occurrences of workplace envy, since group members work closely with one another 
(Duffy \& Shaw, 2000). By working closely, individuals may compare themselves to other members in the group to evaluate their personal attributes, which may increase envy (Greenberg, Aston-James, \& Ashkanasy, 2007). Duffy and Shaw (2000) noted that counterproductive work behavior diplayed by envious people is manifested by exerting less effort and a reduced sense of contribution to a task via social loafing. Hiding information, giving bad advice, or providing misleading information (Fox, Spector, \& Miles, 2001; Vecchio, 2007), would be strategies for envious people to limit their efforts to group task performance. Through social loafing, enviers have difficulty collaborating with others and are willing to undermine or sacrifice oucomes that may also benefit them, as long as it actually affects or harms the envied person (Thompson, Glaso, \& Martinsen, 2016). It is noted that one way to compensate inferior feeling is by harming the other person (Heider, 1958), i.e., through social loafing. Although this counter-productive behavior may seem harmless, it actually diminishes group performance. Similarly, employees who experience greater envy would be likely to foster irrational behaviour and evoke unpleasantness, for instance, interpersonal distrust and hostility among members (Vecchio, 2005).

We propose workplace envy as an important factor of social loafing. Envious employees are more likely to engage in social loafing by decreasing their effort in group work. It is because through social loafing, enviers see this behavior as a response to compensate their feeling of inadequacy (Barth, 1988). This underscores the AET (Weiss \& Cropanzano, 1996) as it predicts and explains how emotional reactions influence workplace attitude and behavior. The AET is a theory of affect (the broader term for emotional experiences, including emotion and mood) in the workplace. In addition to focusing on affect, it encompasses cognitions, behavior, attitude, and other crucial psychological constructs to explain job behavior and performance. The understanding of emotions at work has been significantly augmented by this theory. The AET demonstrates that employees react emotionally to things that happen to them at work and that this influences their job performance and satisfaction. The theory begins by recognizing that emotions are a response to an event in the individual's work environment. The work environment includes everything surrounding the job, like characteristics of the job, including the variety of tasks and degree of autonomy, job demands, and requirements for expressing emotional labor. This environment creates work events that can be hassles or uplifts, or both. 
According to Weiss and Cropanzano (1996), emotions determine affect-driven behavior in the work setting, i.e., there is a relationship between the employees' emotions and their reaction to incidents that happen in the workplace, for example, putting less effort. When applied to the current study, we suggest that the negative mood triggered by workplace envy negatively affects the commitment towards the group (through social loafing). This is supported by Jordan, Lawrence, and Troth (2006) that team members' mood can affect the collaboration among the group members. In addition, we argue that negative mood through workplace envy would be likely to cause a decreased level of helping behaviour among members and reduce the motivation to exert effort to group work (through social loafing). Thus, this will result in individuals withholding their contributions to the group. On the basis of this, we propose:

$\mathrm{H}_{1}$ : Workplace envy is positively related to social loafing.

\section{The Moderating Role of Self-Esteem}

Feelings of envy and self-esteem are often related. It has been observed that negative emotions and self-esteem are associated with social loafing. From article wrote by Vecchio (1995) noted that envious people have a sense of reduced self-worth which may encourage them to focus on their personal shotcomings. It also often reduces the positive feelings about themselves. When working closely with other members, individuals tend to compare themselves to them. This comparison may cause them to feel insecure or anxious about their own worth, which can threaten their self-esteem (Cohen-Charash, 2000). Inability to promote one's values will increase the perceived threat. Envious people may experience lower self-esteem, and that negative experience can drive them to reduce the perceived threat via social loafing (Thompson, Glaso, \& Martinsen, 2016). The study further notes that when envious individuals experience a sense of reduced self-worth, this evaluation of self has a profound impact on social loafing. The enviers would rectify this threat by limiting their contribution and effort to the group. Thus, we assume that by social loafing, enviers contribute less than they otherwise would to a group as a result of feeling reduced self-worth.

According to the AET (Weiss \& Cropanzano, 1996), the sequence of events associated with envy creates an unfavorable social comparison 
that leads to lower self-esteem (Tesser \& Campbell, 1990), which in turn, results in behavioral changes, such as social loafing. Moreover, we assume that the negative social comparison causes self-esteem to appear fragile, and that the person experiencing envy reduces the frustration by exhibiting deviant workplace behavior, for instance, social loafing (Robinson \& Bennett, 1995), which diminishes overall group effectiveness. In this study, we assume that enviers with low self-esteem, are more likely to exhibit social loafing behavior . Conversely, this study suggests that envious individuals with high self-esteem may buffer the negative effect on social loafing. In response, we hypothsize the following:

$\mathrm{H}_{2}$ : Self-esteem moderates the relationship between workplace envy and social loafing, such that the relationship is stronger for those with low rather than high self-esteem.

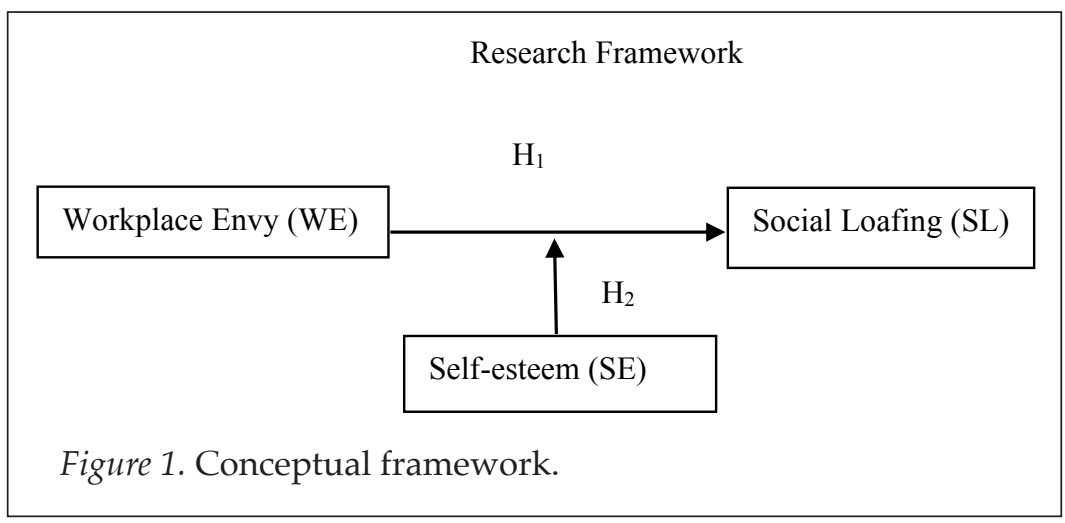

\section{Methodology}

\section{Sample and Procedure}

In order to test the proposed hypotheses, employees working in public and private organizations in Malaysia were surveyed. The data were gathered through the use of a questionnaire distributed either via email or by face-to-face distribution to respondants by using the snowball sampling technique, which is one of nonprobability sampling techniques, where existing study subjects recruit future subjects from among their acquaintances. For the sensitivity of 
this study, we gave assuarance of employees' anonymity and the confidentiality of their responses. In this survey therefore, the respondents were not allowed to mention their names. A total 393 employees returned usable questionnaires that had been distributed, representing a total response rate of 91.5 percent. The majority of respondents are female (60.6\%), Malays (52.4\%), and married $(51.1 \%)$. About 67.2 percent of the respondents reported completing their education at the undergraduate level. Most of the respondents are full-time employees $(94.9 \%)$ and have more than eight years working experience $(35.4 \%)$.

\section{Measures}

Participants completed a survey consisting of demographic characteristics and three validating measures.

Workplace envy: Employee envy was measured using the five-item scale developed by Vecchio (2005) to assess respondents' feelings of envy in the workplace. The respondents were asked to indicate the extent of their agreement or disagreement with each item on a five-point Likert scale, ranging from strongly disagree (1) to strongly agree (5). Two sample items are as follows: 'Most of my co-workers have it better than I do' and "Some of my co-workers are envious of my accomplishments". The cronbach's alpha is reported at 0.80 . Social Loafing. Perceived social loafing is the perception that one or more other group members are contributing less than they could do to the group (Comer, 1995). The current instrument used was adopted from George (1992). The perceived social loafing questionnaire (PSLQ) is a 7-item unidimensional instrument that asks participants to indicate their agreement with the occurrence of social loafing in their group. The respondents were asked to indicate the extent of their agreement or disagreement with each item on a five-point Likert scale, ranging from strongly disagree (1) to strongly agree (5). Higher score indicates higher perception of social loafing among group members. Two sample items are as follows: "Some members of my group put forth less effort than the rest when we work together on the task" and "Some members of my group are free-riders, who rely too much on others to do their share of work". George (1992) reported a cronbach's alpha of the scale at 0.93 in her original article.

Self-esteem: The self-esteem scale was measured using Rosenberg (1965). The scale is the most common measurement to assess self- 
esteem, which has 10 measurement items. Respondents indicate the frequency of their general feelings using a five-point Likert-type scale, ranging from strongly disagree (1) to strong agree (5). Two sample items are as follows: "I am able to do things as well as most other people" and "I feel that I'm a person of worth, at least on an equal plane with others". The Cronbach's alpha reliability is 0.75 .

\section{Data Analysis}

Partial least squares-structural equation modelling (PLS-SEM) with SmartPLS3.0 (Ringle. Wende, \& Becker, 2015) was used to test the hypotheses. Data analysis was carried out in two stages - the measurement and the structural model stages by conducting PLS algorithm and bootstrapping procedure. The objective is to generate estimates that assist in answering the hypotheses. The structural model assessment also includes testing the moderation hypothesis.

\section{Results}

\section{Descriptive and Correlation Results}

Table 1 shows the mean, standard deviation and Pearson Correlations of the study variables. All bivariate relationships among the study variables are statistically significant. The highest correlation is between workplace envy and self-esteem, $r(393)=0.517, p<0.001$; and the lowest correlation is between workplace envy and social loafing, $r(393)=0.379, p<0.001$.

Table 1

Mean, Standard Deviation and Pearson Correlations

\begin{tabular}{llccc}
\hline \multicolumn{1}{c}{ Variable } & Mean & SD & 1 & 2 \\
\hline 1. Workplace envy & 3.24 & 0.67 & & \\
2. Social loafing & 3.07 & 0.65 & 0.379 & \\
3. Self-esteem & 2.41 & 0.59 & 0.517 & 0.407 \\
\hline
\end{tabular}

Note: $\mathrm{N}=393$. All correlations were statistically significant at the 0.001 level. 
IJMS 27(2), 27-46 (2020)

\section{Model Assessment Results}

Table 2 shows the internal consistency reliability of the measurement model. The Cronbach's alpha shows high values at $0.847,0.848$ and 0.813 for self-esteem, social loafing and workplace envy. Likewise, the composite reliability values are high, ranging from 0.861 (workplace envy) to 0.893 (self-esteem). Moreover, the average variance extracted (AVE) values for self-esteem, social loafing and workplace envy are above the 0.50 threshold, which explains that more than half of the respective indicator's variance is explained by its latent variable.

Table 2

Reflective Measurement Model Results

\begin{tabular}{lcllll}
\hline Construct & Item & $\begin{array}{l}\text { Outer } \\
\text { loading }\end{array}$ & $\begin{array}{l}\text { Cronbach's } \\
\text { alpha }\end{array}$ & $\begin{array}{l}\text { Composite } \\
\text { reliability }\end{array}$ & $\begin{array}{l}\text { Convergent } \\
\text { validity }\end{array}$ \\
\hline Self-esteem (SE) & SE2 & 0.708 & 0.847 & 0.893 & 0.626 \\
& SE3 & 0.693 & & & \\
& SE5 & 0.883 & & & \\
& SE6 & 0.842 & & 0.891 & 0.624 \\
Social loafing & SE9 & 0.814 & & & \\
(SL) & SL2 & 0.629 & 0.848 & & \\
& & & & & \\
& SL3 & 0.789 & & & \\
& SL5 & 0.877 & & & \\
& SL6 & 0.778 & & & \\
& SL7 & 0.853 & & & \\
Workplace envy & WE1 & 0.814 & 0.813 & & \\
(WE) & & & & & \\
& WE2 & 0.787 & & & \\
& WE3 & 0.743 & & & \\
& WE4 & 0.651 & & & \\
& WE5 & 0.775 & & & \\
& & & & \\
\end{tabular}

For the indicator level, the results for outer loadings show that most loadings are above the 0.70 threshold value, indicating that the 
indicators are reliable. However, a few indicators of social loafing and self-esteem fall below the threshold value. Based on Hair et al. (2017), removing indicator loadings should only be considered if such removal can assist in increasing the composite reliability above its threshold value. For this study analysis however, the composite reliability is not affected by the lower outer loadings and only convergent validity is found to be below the acceptable value of 0.50 . Thus, the problem indicators were removed one at a time so that the convergent validity meets the threshold value. After the removal process, the result shows the convergent validity for self-esteem and social loafing achieve the threshold value, i.e., above 0.50 as shown in Table 2.

For discriminant validity, the heterotrait-monotrait or HTMT ratio was used. Table 3 provides evidence for discriminant validity and shows the HTMT correlations are below the threshold value of 0.85 .

Table 3

Heterotrait-monotrait (HTMT) Ratio

\begin{tabular}{clcc}
\hline & Workplace envy & Social loafing \\
\hline 1. & Workplace envy & & \\
2. & Social loafing & 0.659 & \\
3. & Self-esteem & 0.352 & 0.365 \\
\hline
\end{tabular}

After assessment of the reliability and validity of the measurement model, the structural model was assessed. Results of the coefficient of determination $\left(R^{2}\right)$ show that the research model explains $35.8 \%$ variation in the social loafing construct. Therefore, the model explains the endogenous constructs moderately well (Chin, 2010).

Table 4 shows that effect size $\left(f^{2}\right)$ of the predictors indicate the presence of small to large effects (Chin, 2010). Specifically, workplace envy has large effect $\left(f^{2}=0.397\right)$ on social loafing and self-esteem has small effect on social loafing $(f=0.038)$. As shown in Table 4 , results of the bootstrapping procedure (cases $=393$, resample $=5000$ ), for testing the significance of the path coefficients show that all direct and indirect paths are significant. 
Finally, in order to examine the model's capability to predict, two approaches were used. The first was the blindfolding procedure with an omission distance of $\mathrm{D}=7$ to generate the cross-validated redundancy $\left(Q^{2}\right)$ values. The value for social loafing is $\left(Q^{2}=0.210\right)$, which is larger than zero, explains that the structural model has predictive relevance. The second approach was PLS. Hair, Hult, Ringle and Sarstedt (2014) stated that as a relative measure of predictive relevance, the small, medium and large predictive relevance values must be $0.02,0.15$ and 0.35 , respectively. Based on the result, this study generated a value of 0.263 for $Q^{2}$, indicating moderate predictive power.

Table 4

Hypothesis Testing Results

\begin{tabular}{llllll}
\hline $\begin{array}{l}\text { Hypothesized } \\
\text { relationship }\end{array}$ & $\begin{array}{l}\text { Path } \\
\text { coefficient }\end{array}$ & $t$-value & $p$-value & $\begin{array}{l}\text { Confidence } \\
\text { intervals (95\%) }\end{array}$ & $\begin{array}{l}\text { Effect } \\
\text { Size - } f\end{array}$ \\
\hline $\begin{array}{l}\mathrm{H}_{1} \text { : Workplace } \\
\text { envy à Social } \\
\text { loafing }\end{array}$ & 0.262 & 3.991 & 0.000 & {$[0.153,0.359]$} & 0.397 \\
$\begin{array}{l}\mathrm{H}_{2} \text { : Self-esteem } \\
\text { x Workplace } \\
\text { envy àSocial }\end{array}$ & 0.249 & 6.524 & 0.000 & {$[0.183,0.313]$} & 0.038 \\
loafing & & & & & \\
\hline
\end{tabular}

\section{Hypothesis Testing Results}

Overall, the results for hypothesis testing are statistically significant at the .000 level. Specifically, the relationship between workplace envy and social loafing is statistically significant $(\beta=0.262, p<0.000)$. Hence, Hypothesis 1 that there is a direct and positive relationship between workplace envy and social loafing is supported. Hypothesis 2 proposed that self-esteem moderates the relationship between workplace envy and social loafing. The result from bootstrapping procedure shows that the path coefficient is statistically significant $(\beta=0.249, p<0.000)$. Therefore, Hypothesis 2 is supported. 


\section{Discussion}

In this study we examined the relationship between workplace envy, and social loafing and self-esteem. We found that workplace envy has a positive effect on social loafing (Hypothesis 1), and that selfesteem moderates the relationship between workplace envy and social loafing, such that the relationship is stronger for those with low rather than high self-esteem (Hypothesis 2). For Hypothesis 1 , the finding supports the idea that envious employees engage in a counterproductive response, i.e., social loafing (Thompson, Buch, \& Glaso, 2018). This finding suggests that the argument developed by Vecchio (2005) about the impact of workplace envy on social loafing is significant as it is seen as a possible behavioral coping response to envy. Previous research in this area has produced consistent results for the relationship between workplace envy and social loafing (see Duffy \& Shaw, 2000; Thompson, Glaso, \& Martinsen, 2016; Rutte, 2013; Ganegoda \& Bordia, 2019 ). When envy is high among certain individuals in a group, they will often look for means to exert the least amount of contribution and adversely affect performance in teams.

Hypothesis 2 suggests self-esteem moderates the relationship between workplace envy and social loafing; such that the relationship is stronger for those with low rather than high self-esteem. Dogan and Vecchio (2001) noted that envy stimulates a sense of insecurity among envious employees as a response to a perceived treat. Based on this argument, through social comparison, envious employees feel that such a situation threatens their self-worth and reduces their self-esteem. These threats might manifest hostile behavior among employees to some degree (Bedeian, 1995). Consistent with others (see Cohen-Charash, 2000; Glaso \& Martinsen, 2016), an increased level of workplace envy therefore seems to foster less team collaboration due to social loafing, and such condition becomes stronger when the feeling of reduced self-esteem among envious employees increases. Explanation for these findings is also found in the AET (Weiss \& Cropanzano, 1996). As discussed, workplace events cause negative emotional responses on the part of employees, such as workplace envy, which then influences workplace attitude and behavior, such as social loafing. Feeling envious may lead to an unfavorable focus on personal shortcomings, such as diminished self-esteem, thus influencing deviant team behaviour, such as social loafing, to rectify the perceived treat. 


\section{Theoretical and Practical Implications}

There are a few theoretical implications from the results of this study. First, this study adds to the existing body of knowledge on negative emotions, such as feeling envious, which can be dangerous in the workplace as it can lead to low self-esteem among members and cause dysfuntional team cooperation. No research has looked into the relationship between workplace envy and social loafing to the best of our knowledge. This research is the first study to investigate and empirically confirm the predictive effect of workplace envy on social loafing. This directs potential researchers to further investigate the underlying relationship process between these two variables. Second, in describing workplace envy and its consequences, the study adds to the AET literature by providing evidence of the theory's applicability in understanding the relationship between these variables. This theory predicts and explains how emotional reactions influence workplace attitude and behavior. According to Weiss and Cropanzano (1996), emotions determine affect-driven behavior in the work setting, and there is a relationship between the employees' emotions and their reactions to incidents that happen in the workplace, such as transient effort. When applied to the current study, we suggest that the negative mood triggered by workplace envy affects negatively the commitment towards the group (through social loafing). Third, the present study focuses not only on understanding the negative effect of envy, but also on how to mitigate it by analyzing individual factors that could improve the relationship.

The findingsclearly indicate that workplaceenvy serves as animportant antecedent of social loafing. Futhermore, this study shows that feelings of envy at work would be dangerous as it hurts individuals' selfesteem, thus causing a dysfunctional team cooperation. Practically, it is important to understand the circumstances of social loafing as a means to control or facilitate a coping mechanism for employees who are experiencing workplace envy that reinforces reduced selfesteem. Organizations should etablish a supportive workplace that encourages employees to be more involved and practice openness and give continued support (Varshney, 2018). In a team culture especially, managers must play an active role by paying attention and being more sensitive towards circumstances that induce feelings of envy at work. By implementing a proper system and control, the tendency towards 
workplace envy can be mimimized (Kim, O’Neill, \& Cho, 2010). To do so, open effective communication should be encouraged among team members where they are free to voice out their concerns and discuss any problem the team members may be experiencing. Such a practice to incorporate feedback may reduce the feeling of resentment among employees, which may have a detrimental effect on team cooperation. In addition, to minimize workplace envy and social loafing, it is important to promote team interdependence among members (Van Dick, Tissington, \& Hertel, 2009). Interdependent teams offer high coherence as it encourages shared ownership of the goals among the team members and coordination of shared resources. In terms of boosting self-esteem, team members can empower one another by offering support and encouragement to help members realize their potential and to trust their abilities.

\section{Limitations and Further Research}

Like many other studies, this paper has several limitations, First, although our data collection was spread over time, the design of the study is definitely not longitudinal. This study, we believe, could benefit more from a longitudinal design to test the hypotheses. Future studies can adopt the approach to reaxamine this model. Second, the results are focused on cross-sectional and self-report data, resulting in common method error due to the possibility of origin bias. Because of the respondents "inability to respond correctly, the observed relationship may have been artificially inflated. Future studies can therefore use different methods to gather data in order to eliminate this bias.

\section{Conclusion}

In conclusion, the present study provides empirical evidence on the relationship between contextual and individual factors by investigating the relationship between workplace envy and social loafing behavior among employees. Although workplace envy is a low-intensity type of interpersonal activity, negative emotions have a significant impact on employee behavior. The negative effects on envy go beyond members' inability not to put high effort when working in 
teams, which can affect organizational efficiency over the long-term. However, our study indicates the important functions of personality traits to show the significance of individual differences in predicting employee actions in the workplace.

\section{Acknowledgement}

This research received no specific grant from any funding agency.

\section{References}

Aggarwal, P., \& O’Brien, C. L. (2008). Social loafing on group projects: Structural antecedents and effect on student satisfaction. Journal of Marketing Education, 30(3), 255-264.

Barth, D. F. (1988). The role of self-esteem in the experience of envy. American Journal of Psychoanalysis, 48, 198-210.

Bedeian, A. G. (1995). Workplace envy. Organizational Dynamics, 23(4), 49-56.

Chin, W. W. (2010). How to write up and report PLS analyses. In Handbook of partial least squares (pp. 655-690). Springer, Berlin, Heidelberg.

Cohen-Charash, Y. (2000). Envy at work: A preliminary examination of antecedents and outcomes (Unpublished doctoral dissertation). University of California, Berkeley.

Cohen-Charash, Y., \& Mueller, J. S. (2007). Does perceived unfairness exacerbate or mitigate interpersonal counterproductive work behaviors related to envy? Journal of Applied Psychology, 92(3), 666.

Colquitt, J. A., Conlon, D. E., Wesson, M. J., Porter, C. O. L. H., \& Ng, K. Y. (2001). Justice at the millennium: A meta-analytic review of 25 years of organizational justice research. Journal of Applied Psychology, 86(3), 425-445.

Comer, D. R. (1995). A model of social loafing in real work groups. Human Relations, 48(6), 647-667.

Dogan, K., \& Vecchio, R. P. (2001). Managing envy and jealousy in the workplace. Compensation \& Benefits Review, 33(2), 57-64.

Duffy, M. K., \& Shaw, J. D. (2000). The salieri syndrome: Consequences of envy in groups. Small Group Research, 31(1), 3-23. 
Duffy, M. K., Shaw, J. D., Scott, K. L., \& Tepper, B. J. (2006). The moderating roles of self-esteem and neuroticism in the relationship between group and individual undermining behavior. Journal of Applied Psychology, 91(5), 1066-1077.

Duffy, M. K., Shaw, J. D., \& Schaubroeck, J. M. (2008). Envy in organizational life. In R. H. Smith (Ed.), Series in affective science. Envy: Theory and research (pp. 167-189). New York, NY, US: Oxford University Press.

Erdil, O., \& Müceldili, B. (2014). The effects of envy on job engagement and turnover intention. Procedia - Social and Behavioral Sciences, 150, 447-454. https://doi: 10.1016/j.sbspro.2014.09.050

Fox, S., Spector, P. E., \& Miles, D. (2001). Counterproductive work behavior (CWB) in response to job stressors and organizational justice: Some mediator and moderator tests for autonomy and emotions. Journal of Vocational Behavior, 59, 291-309.

Fishbein, M., \& Ajzen, I. (1977). Belief, attitude, intention, and behavior: An introduction to theory and research. Retrieved from https:// www.researchgate.net/publication/ 233897090_

George, J. M. (1992). Extrinsic and intrinsic origins of perceived social loafing in organizations. Academy of Management Journal, 35(1), 191-202.

González-Navarro, P., Zurriaga-Llorens, R., Tosin Olateju, A., \& Llinares-Insa, L. I. (2018). Envy and counterproductive work behavior: The moderation role of leadership in public and private organizations. International Journal of Environmental Research and Public Health, 15(7), 1455. https://doi:10.3390/ ijerph15071455

Ganegoda, D. B., \& Bordia, P. (2019). I can be happy for you, but not all the time: A contingency model of envy and positive empathy in the workplace. Journal of Applied Psychology, 104(6), 776.

Greenberg, J., Aston-James, C. E., \& Ashkanasy, N. M. 2007. Social comparison processes in organizations. Organizational Behaviour and Human Decision Processes, 102, 22-41.

Hair, J., Hult, T., Ringle, C., \& Sarstedt, M. (2014). A Primer on Partial Least Squares Structural Equation Modeling (PLS-SEM). Thousand Oaks, CA: Sage Publications, Inc.

Hair Jr, J. F., Matthews, L. M., Matthews, R. L., \& Sarstedt, M. (2017). PLS-SEM or CB-SEM: updated guidelines on which method to use. International Journal of Multivariate Data Analysis, 1(2), 107123.

Hökkä, P., Vähäsantanen, K., \& Paloniemi, S. (2019). Emotions in learning at work: A literature review. Vocations and Learning, $1-26$. 
Heider, F. (1958). The psychology of interpersonal relations. Hoboken, NJ, US: John Wiley \& Sons.

Jassawalla A., Sashital H. \& Malshe A. (2009) Students' perceptions of social loafing: Its antecedents and consequences in undergraduate. Operations Management, 8(1), 42-54.

Jordan, P. J., Lawrence, S. A., \& Troth, A. C. (2006). The impact of negative mood on team performance. Journal of Management $\mathcal{E}$ Organization, 12(2), 131-145.

Judge, T. A., Van Vianen, A. E. M., \& De Pater, I. E. (2004). Emotional stability, core self-evaluations, and job outcomes: A review of the evidence and an agenda for future research. Human Performance, 17(3), 325-346.

Kim, S., O'Neill, J. W., \& Cho, H. M. (2010). When does an employee not help coworkers? The effect of leader-member exchange on employee envy and organizational citizenship behavior. International Journal of Hospitality Management, 29(3), 530-537.

Mouly, V. S., \& Sankaran, J. K. (2002). The enactment of envy within organizations: Insights from a New Zealand academic department. Journal of Applied Behavioral Science, 38(1), 36-56.

Parrott, W. G., \& Smith, R. H. (1993). Distinguishing the experiences of envy and jealousy. Journal of Personality and Social Psychology, 64(6), 906-920.

Pearson, C. M. (2017). The smart way to respond to negative emotions at work. MIT Sloan Management Review, 58(3), 49-56.

Porath, C. L., \& Pearson, C. (2012). Emotional and behavioral responses to workplace incivility and the impact of hierarchical status. Journal of Applied Social Psychology, 42(SUPPL. 1).

Ringle, C. M., Wende, S., \& Becker, J. M. (2015). SmartPLS 3. SmartPLS GmbH, Boenningstedt. Journal of Service Science and Management, 10(3).

Rosenberg, M. (1965). Rosenberg self-esteem scale (SES). Society and the adolescent self-image. Princetion, New Jersey: Princeton University Press.

Robinson, S. L., \& Bennett, R. J. (1995). Atypology of deviantworkplace behaviors:A multidimensional scaling study. Academy of Management Journal, 38, 555-572.

Rutte, C. G. (2003). Social loafing in teams. International handbook of organizational teamwork and cooperative working. https://doi. org/10.1002/9780470696712.ch17

Satvir, S., Huaqing, W., \& Min, Z. (2017). Perceptions of social loafing in groups: Role of conflict and emotions. http://dx.doi. org/10.2139/ssrn.3132871 
Shu, C.-Y., \& Lazatkhan, J. (2017). Effect of leader-member exchange on employee envy and work behavior moderated by selfesteem and neuroticism. Journal of Work and Organizational Psychology, 33(1), 69-81.

Smith, R. H., \& Kim, S. H. (2007). Comprehending envy. Psychological Bulletin, 133, 46-64.

Tai, K., Narayanan, J., \& McAllister, D. J. (2012). Envy as pain: Rethinking the nature of envy and its implications for employees and organizations. The Academy of Management Review, 37(1), 107-129.

Tracy, J. L., \& Robins, R. W. (2003). Death of a (narcissistic) salesman: An integrative model of fragile self-esteem. Psychological Inquiry, 14, 57-62

Tesser, A., \& Campbell, J. (1990). Self-definition: The impact of the relative performance and similarity of others. Social Psychology Quarterly, 43, 341-347.

Thompson, G., Buch, R., \& Glasø, L. (2018). Follower jealousy at work: A test of Vecchio's Model of antecedents and consequences of jealousy. The Journal of Psychology, 152(1), 60-74.

Thompson, G., Glaso, L., \& Martinsen, O. (2016). Antecedents and consequences of envy. The Journal of Social Psychology,156(2), 139-153.

Tyng, C. M., Amin, H. U., Saad, M., \& Malik, A. S. (2017). The influences of emotion on learning and memory. Frontiers in Psychology, 8, 1454. https://doi.org/10.3389/fpsyg. 2017.01454

Uysal, H. T. (2019). The effect of social loafing perception to workers' feelings of burnout in organisations. Retrieved fromhttps://www. researchgate.net/publication/309763764

Van Dick, R., Tissington, P. A., \& Hertel, G. (2009). Do many hands make light work? How to overcome social loafing and gain motivation in work teams. European Business Review, 21(3), 233-245.

Varshney, D. (2018). Relationship between social loafing and the selfconcept. Journal of Indian Business Research. https://doi:10.1108/ jibr-11-2017-0230

Vecchio, R. (2005). Explorations in employee envy: Feeling envious and feeling envied. Cognition \& Emotion, 19(1), 69-81.

Vecchio, R. P. (1995). It's not easy being green: Jealousy and envy in the workplace. Research in Personnel and Human Resources Management, 13, 201-244. 
IJMS 27(2), 27-46 (2020)

Vecchio, R. P. 2007. Cinderella \& Salieri in the workplace: The envied and the envier. In S. W. Gilliland, D. D. Steiner, \& D. P. Skarlicki (Eds.), Managing social and ethical issues in organizations (pp109134). Information Age.

Weis, H., \& Cropanzano, R. (1996). Affective events theory: A theoretical discussion of the structure, causes and consequences of affective experiences at work. Research in Organizational Behavior, 18, 1-74. 